\title{
Creativity in Higher Education
}

\author{
Drazena Gaspar ${ }^{*}$, Mirela Mabic \\ Faculty of Economics, University of Mostar, Matice Hrvatske bb, Mostar, Bosnia and Herzegovina
}

Copyright (C) 2015 by authors, all rights reserved. Authors agree that this article remains permanently open access under the terms of the Creative Commons Attribution License 4.0 International License

\begin{abstract}
The paper presents results of research related to perception of creativity in higher education made by the authors at the University of Mostar from Bosnia and Herzegovina. This research was based on a survey conducted among teachers and students at the University. The authors developed two types of questionnaires, one for teachers and the other for students in order to investigate the perception about creativity at the University. Namely, the idea that higher education has key role in development of knowledge-based society and economy has been in the very heart of Bologna process - the overall reform of the higher education in European Union. Also, many official European Union documents identified creativity as a major driving force towards knowledge creation and social and economic advancement through the development of a knowledge society. But, the complex questions of knowledge-based society and economy could not be solved without creative, forward-looking individuals and groups who are not afraid to question established ideas and who are able to cope with the insecurity and uncertainty this entails. If today's universities, including University of Mostar, would not succeed in strengthening creativity of teaching process and education of their teachers and students, development of knowledge society could be at stake. The University of Mostar has been started with implementation of the main postulates of Bologna process since 2005. Almost ten years later, the authors wanted to examine if teachers and students of the University of Mostar are aware of the importance of creativity in higher education for development of knowledge society. That was the main reason why the authors started with research related to perception of creativity at the University of Mostar. The aim of this research was to investigate the awareness of teachers and students of the University related to the necessity to enhance creativity within and by academic community.
\end{abstract}

Keywords Creativity, Higher Education, Knowledge -based Society

\section{Introduction}

In the last decade creativity has become a mantra which is used by politicians, businessmen, employees, teachers, professors, students and others. Creativity is seen as a cure for a wide range of problems like social, economic and educational.

Creativity specifically has become a critical consideration, because "creativity becomes a force of great value when it is applied to causes that benefit humankind and the world at large" [1].

In Learning and Teaching, the traditional teacher centered, transmission model of learning adopted by the 'sage on the stage' [2] has gradually begun to change to a more facilitative approach to teaching that is learner centered and where the teacher becomes the 'guide on the side'. Barr and Tagg [2] see this shift from an 'instructional' to a 'learning' paradigm as changing the role of higher education (HE) from a 'place of instruction' to a place to 'produce learning'. Given greater democracy in learning, McWilliam [2] suggests that the teacher can become the co-creator of new meaning making. Pressures for status quo in the socio-economic structures, the training needs of the economy, the co-modification of learning and the learner and adherence to traditional teaching methods that retain the power of the teacher, all support the passive receptor model of the learner who can then only learn that which is already known. This historical model of performance, though much loved by traditionalists, singularly fails to prepare learners to be creative in a life of change [2]. It is obvious that citizens of an increasingly complex community, country and globalized world need the skills, critically reflective processes and creative approaches in order to cope successfully.

Since 2005 University of Mostar has started formally with implementation of Bologna process (the overall reform of the higher education in European Union with the main aim to establish common European Higher Education and Research Area), although University has observed European trends in higher education from the very beginning. The last Strategy of development University of Mostar 2012-2016 (Strategy) was following modern trends in higher education related to the role of universities in social and economic development and need for improvement of creativity. In Strategy is said "Through creation of new ideas and technological solutions, critical thinking and creativity, University will become one 
of the key drivers of economy and sustainable development and at the same time it will foster and work on preserving cultural and historical heritage of social community from which is originated [3]. Although is Strategy publicly presented, discussed and adopted by University Senate, it is general opinion that traditional attitudes towards knowledge transfer by lecture, however, still pervade many disciplines at the University. That was the main reason why the authors started with research related to perception of creativity at the University. That was the first research of that type at the University of Mostar and it was based on a survey conducted among teachers and students at the University. The authors developed two types of questionnaires, one for teachers and the other for students in order to investigate the perception about creativity at the University. Two questionnaires were used because of different general information about teachers and students.

In the paper are presented results of this preliminary research which had aim to investigate the awareness of teachers and students of the University related to the necessity to enhance creativity within and by academic community.

\section{Concept of Creativity}

Term creativity has root in a Latin word "creare" which means produce something. Latin poet Horatio wrote that poets and painters have talent to create something new. But, in Christian period word "creation" got completely different meaning. It was used to describe God act of creation, not human [4]. Modern approach to creativity has started with theory of Graham Walas published in his book "Art of Thought" in 1926. He explained model for the four stages of creativity: preparation, incubation, illumination and verification. But, formal start of scientific research of creativity was imputed to J.P. Guilford. Guilford made an important contribution to understanding of creativity when he distinguished between convergent and divergent thinking processes. Convergent thinking, usually deductive, is thinking in which ideas are examined for their logical validity or in which a set of rules is followed while divergent thinking is an unusual and un-stereotyped way of thinking which generates several possible solutions to problem. Emphasis on divergent thinking and novelty is consistent with the typical layperson's conception of creativity but problematic when the solution must be both novel and effective [5]. Creativity occurs on the right side of the brain when ideas are sparked, but to make creativity useful requires both divergent thinking (generating many unique ideas) and convergent thinking (combining those ideas into the best result) [1].

There are a number of definitions of creativity, depending on different authors. Stjepan Ozimec said that "Creativity is a such kind of creation by which one produce something new, different from known, which include individual way of problem solving, discovery of unknown" [6]. As Isaksen said, creativity is not unambiguous phenomenon which could be defined precisely [7].

The physicist David Bohm saw creativity as dependant on perception and ability to recognize something new, requiring a state of mind which is 'attentive, alert, aware and sensitive' and does not impose existing preconceptions. This is very similar to the state which the educationalist Mezirow says is necessary for transformational learning to take place in which a person may have to abandon or modify their values and beliefs in order to accommodate their new experience and to create a new meaning. Bohm sees creativity as potentially opening the way to transform the individual [8].

More importantly, educators will have their own implicit definition of creativity that will influence their acceptance of creativity as an important skill to be taught [5]. In contrast to the popular view in which creativity is characterized as merely weird or non-conformist, an appropriate definition for educators focuses on the process culminating in a novel and effective solution to an open-ended problem. The importance of both novelty and effectiveness is reflected in the following definition. Creativity is "... the ability to produce work that is both novel (i.e. original, unexpected) and appropriate (i.e. useful, adaptive concerning task constraints)" [5].

\section{The Importance of Creativity in Higher Education}

Higher education has been paying attention to the creativity when it was faced with large economic, cultural and other macro-environmental challenges which are changing role of universities from classical research universities (,,ivory towers") to entrepreneurial universities in the way that they not only became autonomous in their decisions, but also in the way that they developed and implemented new research and transfer relationships within their respective regions.

Livingston identified rising costs, increasing direct competition between universities, indirect competition from easily accessible alternative forms of learning, off-campus education possibilities such as the Internet as just a few modern challenges faced by university [9]. This leads modern universities to the ultimate challenge, staying relevant and becoming redundant in a highly competitive market. In this regard, competitiveness expands to additional factors such as off-curriculum activities, innovative and new modules, sport development, development of reading skills, ease of information access and a safe, conducive learning environment [1]. One such additional factor is the addition of creativity as stimulus in the development of the university student [1].

Almost all European strategic documents related to higher education mentioned creativity as imperative precondition for its further development. Document Lisbon Declaration Europe's Universities beyond 2010: Diversity with a common purpose from the year 2007 stressed the need for 
"strong universities for Europe" [10] enable "to produce an institutional milieu favorable to creativity, knowledge creation and innovation" [10].

European Commission in Document EUROPE 2020 - A strategy for smart, sustainable and inclusive growth state as one of the three priorities: "smart growth - developing an economy based on knowledge and innovation" which means "strengthening knowledge and innovation as drivers of our future growth. This requires improving the quality of our education, strengthening our research performance, promoting innovation and knowledge transfer throughout the Union, making full use of information and communication technologies and ensuring that innovative ideas can be turned into new products and services that create growth, quality jobs and help address European and global societal challenges. But, to succeed, this must be combined with entrepreneurship, finance, and a focus on user needs and market opportunities" [11]. It is obvious that the role of European universities is crucial in the further development of EU. European Commission in the document Europe 2020 Flagship Initiative from 2010 said that to achieve Innovation Union EU Member states need the following: "Our strengths in design and creativity must be better exploited. We must champion social innovation. We must develop a better understanding of public sector innovation, identify and give visibility to successful initiatives, and benchmark progress [11]. Document Smart People for Smart Growth is statement by the European University Association (EUA) on the EU Flagship Initiative "Innovation Union" of the Europe 2020 European Strategy for Smart, Sustainable and Inclusive Growth. First of six key messages was that "Europe's universities play an essential role in the "innovation chain" through their research and teaching activities which strengthen our knowledge base and skill development to provide new jobs for the future" [12]. Part six of that Document is dedicated to "Promoting openness and capitalizing on Europe's creative potential" [12].

"Creativity in Higher Education", a project initiated by the EUA and cofunded by the Socrates Programme of the European Commission, was designed as an exploratory activity to enhance understanding of the concept. The aim of the project was to contribute to the advancement of the European knowledge society by identifying good practices and providing higher education institutions and their major external stakeholders - governments, quality assurance agencies and other partners - with operational recommendations on how to foster creativity [13]. Among ten key recommendations to European higher education institutions which have been derived from the findings and conclusions of the Creativity Project, the following are related to creativity [13]:

- Striving towards a creative mix of individual talents and experiences among students and staff, providing common fora for researchers from different disciplines and offering diverse learning experiences will likely result in conditions favourable to the creativity of the higher education community.
- It is recommended that HEIs explore the concept of a learning organisation for their management and governance structures. As important as these structural elements are, they must be complemented with ethical and cultural concerns in order to create an institutional milieu favourable to creativity.

In order to build upon EUA's recent work in enhancing the relationship between quality assurance processes, creativity and innovative practices, EUA launched a project in 2007, entitled Quality Assurance for the Higher Education Change Agenda (QAHECA). QAHECA aimed to explore what kind of quality processes for teaching and learning, both internal and external, support creative and innovative higher education institutions and seeks to limit the potentially problematic effects of these processes. Recommendation directly related to creativity said „, Quality assurance should be inclusive. A key success factor for an efficient quality assurance (QA) that enhances creativity at institutional level implies engaging the whole institutional community and not just considering QA as the special purview of a specific QA unit. This approach regards, for example, strategic planning, educational development and staff development as part of QA processes. We also urge the QA agencies to revisit their standards and processes in order to analyse in which ways they can encourage institutions to adopt this approach" [13].

It is obvious that the mentioned EU documents and projects just gave general recommendations for fostering creativity at HEIs. Unfortunately, they did not offer any analysis of eventual obstacles and limitations that could arose in implementation of those recommendations. One other research, "The State of Creativity in Education" was conducted among individuals (1014 educators) in the field of education across 13 countries (Australia, New Zealand, China, Hog Kong, Taiwan, India, Philippines, Indonesia, Vietnam, Thailand, Malaysia, Singapore and South Korea) in the Asia-Pacific region in 2013. The main goal of this survey was to probe respondents on their attitudes, goals, challenges and needs in the area. Faculty, administrators and other members of the primary, secondary and higher educational structures of their countries, answered a series of fifteen questions related to creativity in schools: current practices, goals, the impact on broader innovation and more [14]. The main results of survey were following [14]:

- Uncovered strong support for creativity in the classroom (62\% educators strongly felt that they should be creative regardless of the subjects they teach).

- The important role of the educator in the process of fostering creativity (a significantly higher number of respondents, $35 \%$ versus $21 \%$, held that educators, rather than parents were primarily responsible for this activity).

- The importance of proper tools and training (41\% educators believe that tools and training for educators are the most critical need to promote creativity).

- Digital tools and technology are important in enabling or facilitating creativity $(85 \%$ respondents felt that 
technology and digital tools play an important role, while $34 \%$ indicated that they were prepared to adapt their teaching methodology to leverage digital tools).

- The recognition of the main constraints imposed by education system ( $57 \%$ are hamstrung by an education system that is not geared towards creativity, $49 \%$ blame it on lack of resources, $29 \%$ blame it on lack of time an $36 \%$ believe that the biggest barrier to creativity is a system that is heavily reliant on testing and assessment).

The main values of this research are that it highlighted the importance of teachers (educators) in fostering creativity and that it was clearly identified basic limitations for implementation of creativity, especially those related to education systems. Those findings could help other education institutions to make deeper analysis of themselves and their education systems regarding creativity.

As it is already mentioned, University of Mostar has continuously observed European and other trends in higher education in order to be in step with good European and world practices. Although joining of Bosnia and Herzegovina $(\mathrm{BH})$ to European Union is very uncertain, academic community of $\mathrm{BH}$ does not want to get behind European higher education institutions, but want to be prepared for joining in European Higher Education Area. University of Mostar is trying to be leading institution on that path.

\section{Materials and Methods}

The research was conducted on a convenience sample of teachers and students at different faculties of the University of Mostar. Participants in research were informed of its purpose and participated voluntarily. Two types of questionnaires were developed, one for teachers and other for students. Generally, questionnaire had two main parts. First part contained general information about respondents while second part contained four groups of questions/ statements. As it was already mentioned, the difference between two types of questionnaire lied just in the first part. Namely, the general information related to students covered following: faculty, type of study (bachelor or master), field of study and study year. The general information related to teachers covered: type of teacher (professor/assistant), teaching field, age, teaching experience and overall working experience. The second part of questionnaire was the same for both, teachers and students. The first group of questions/statements evaluated frequency of practicing specified activities related to creativity. The second group of questions/statements evaluated the frequency of students' involvement during the class. The third group was related to expressing a degree of agreement with a set of statements about creativity in the classroom while the fourth group of statements offered respondents possibility to choose one or more of definition of the term creativity. The frequency of use and degree of agreement were scored according to the
Likert scale with grades from 1 (never/totally disagree) to 5 (always/strongly agree).

After the technical control of questionnaires, sample consisted of 445 questionnaires - 58 questionnaires completed by teachers and 387 questionnaires completed by students. Data were analyzed in Microsoft Office Excel 2007 and SPSS for Windows, version 17.0. Results were expressed in absolute (f) and relative frequencies (\%), also mean and standard deviation $(\mathrm{M} \pm \mathrm{SD})$ were calculated. The differences in the attitudes of teachers and students were tested by t-test for independent samples. The level of significance was $p=0.05$. $P$ values that could not be expressed by three decimal places were reported as $p<0.001$.

\subsection{Research Results}

As noted in previous paragraph, the second part of questionnaire contained four groups of questions/statements about creativity, so results of research are presented in the same manner. The first group of questions/statements was related to the evaluation of the frequency of application of specified activities during class - teaching process. Both, teachers and students evaluated to what extent specified activities appeared during teaching classes, i.e. meaning to what extent teachers practiced them. Results are presented in the Table 1.

Evaluation of teachers' behavior related to creativity during the teaching process shows that there is statistically significant difference in opinions between teachers and students for each activity stated in Table 1 . In the most cases teachers gave better grades, so one could conclude that teachers thought that their lectures are creative and customized to students' needs because they often behave according to specified activities (Table 1). Students' grades were not so high. They thought that teachers were not often affable, nor interested for students' ideas. According to students' opinions teachers do not respect unusual students' questions, do not give creative examples, teachers are not open for new solutions or acceptance of different opinions. Comparison of average grades, beside statistical significant differences, shows that the greatest difference between teachers and students opinions is related to activity "Teachers encourage communication between and with students" while the minimal difference is for activity "Teachers are questioning all known in theory to encourage student on thinking". There is difference between teachers' and students opinions related to practicing all specified activities, except one. Also, there is difference on activity "Teachers suggest students to think like them". Namely, students' opinion is that teachers more often "force" them to think like them, while teachers' opinion are that they do this seldom. From the results presented in Table 1 one could not conclude that there is no creativity in teaching process at University of Mostar. Namely, from the opinions of teachers and students it could be concluded that teachers try to be creative and to raise dynamic of teaching process, but it is obvious that they do not think that it is enough and that there is no room from improvement. 
Table 1. Results related to frequency of practicing specified activities during class

\begin{tabular}{|c|c|c|c|}
\hline \multirow{2}{*}{ Statement } & \multicolumn{2}{|c|}{$\mathbf{M} \pm \mathbf{S D}$} & \multirow{2}{*}{$\mathbf{P}^{*}$} \\
\hline & $\mathbf{T}(\mathbf{n}=\mathbf{5 8})$ & $S(n=387)$ & \\
\hline Teachers appreciate the unusual questions. & $4,138 \pm 0,826$ & $2,964 \pm 1,131$ & $<\mathbf{0 , 0 0 1}$ \\
\hline Teachers appreciate imaginative and unusual ideas. & $4,207 \pm 0,811$ & $2,987 \pm 1,083$ & $<\mathbf{0 , 0 0 1}$ \\
\hline Teachers show students that their ideas have value. & $4,379 \pm 0,721$ & $3,261 \pm 1,068$ & $<\mathbf{0 , 0 0 1}$ \\
\hline Teachers are connected with the evaluation of the causes and consequences. & $3,966 \pm 0,878$ & $2,920 \pm 0,885$ & $<\mathbf{0 , 0 0 1}$ \\
\hline Teachers engage a more detailed discussion of others' ideas. & $3,569 \pm 0,797$ & $2,917 \pm 1,055$ & $<\mathbf{0 , 0 0 1}$ \\
\hline Teachers suggested students to think like them & $2,431 \pm 0,975$ & $3,346 \pm 1,117$ & $<0,001$ \\
\hline Teachers allow students to express their creativity & $4,345 \pm 0,785$ & $3,382 \pm 1,137$ & $<\mathbf{0 , 0 0 1}$ \\
\hline Teachers use case studies from real world as learning tools & $4,448 \pm 0,680$ & $3,282 \pm 1,087$ & $<\mathbf{0 , 0 0 1}$ \\
\hline Teachers show their creativity & $3,931 \pm 0,835$ & $3,163 \pm 1,044$ & $<0,001$ \\
\hline Teachers encourage communication between and with students & $4,466 \pm 0,842$ & $3,044 \pm 1,156$ & $<\mathbf{0 , 0 0 1}$ \\
\hline Teachers encourage students to develop self-confidence to work in unpredictable situations. & $4,172 \pm 0,861$ & $2,897 \pm 1,147$ & $<0,001$ \\
\hline Teachers provide learning situations in which there are no correct answers. & $3,241 \pm 1,144$ & $2,638 \pm 0,970$ & $<0,001$ \\
\hline Teachers are friendly to different new solution and accept different opinions. & $4,362 \pm 0,693$ & $3,103 \pm 1,018$ & $<0,001$ \\
\hline Teachers are questioning all known in theory to encourage student on thinking & $3,603 \pm 1,059$ & $3,072 \pm 1,060$ & $<0,001$ \\
\hline
\end{tabular}

$\mathrm{T}$ - Teacher; S - Student; M-mean; SD - standard deviation;

*t-test for independent samples

The second group of statements evaluated the frequency of students' involvement during the classes. The results are presented in Table 2 .

Table 2. Results related to frequency of students' involvement during the classes

\begin{tabular}{|c|c|c|c|}
\hline \multirow{2}{*}{ During the course, students are encouraged to } & \multicolumn{2}{|c|}{ M \pm SD } & \multirow{2}{*}{ P* } \\
\cline { 2 - 3 } & $\mathbf{T}(\mathbf{n}=\mathbf{5 8})$ & $3,013 \pm 1,017$ & $<\mathbf{0 , 0 0 1}$ \\
\hline participate in a constructive discussion & $4,466 \pm 0,655$ & $3,145 \pm 1,096$ & $<\mathbf{0 , 0 0 1}$ \\
\hline express their views & $4,534 \pm 0,655$ & $3,168 \pm 1,046$ & $<\mathbf{0 , 0 0 1}$ \\
\hline express their own ideas & $4,586 \pm 0,622$ & $3,049 \pm 0,982$ & $<\mathbf{0 , 0 0 1}$ \\
\hline give constructive suggestions & $4,586 \pm 0,676$ & $3,101 \pm 1,034$ & $<\mathbf{0 , 0 0 1}$ \\
\hline give new solutions of problems & $4,431 \pm 0,752$ & $3,829 \pm 1,102$ & $<\mathbf{0 , 0 0 1}$ \\
\hline guide classes to be of interest for them & $3,931 \pm 0,934$ & 2,8 & \\
\hline
\end{tabular}

T - Teacher; S - Student; M-mean; SD - standard deviation;

*t-test for independent samples

As expected, teachers and students evaluated differently encouragement of students on participation during the classes. Looking at average grades at range from 1 (never) to 5 (always) it is visible how teachers thought that they were dedicated to students and encouraged them to participate in discussions, to express their ideas and views, to give proposals and solutions. Average grades for specified activities are around 4.5 with relatively low standard deviations which mean very small variations in answers of teachers. When the encouraging of students to guide classes to be of interest for them (in the framework of course) is in question, the results show a little lower average grade, but it could be concluded that teachers are open for students interests, of course in the framework of courses. Namely, it is obvious that teachers are aware how teaching process does not mean just ex cathedra knowledge transfer, but encouragement and development of students thinking about theme of lecture. Variations of teachers' opinions for these activities are greater than for others. From the students' standpoint, the analysis of frequency related to encouragement of students to activities specified in Table 2 showed up considerably worse grades. Average grades are around 3 which indicate that, according to students' opinion, teachers did not often encourage students to actively participate at classes. Generally, students think that teachers do not encourage them enough to be active participants of teaching process which leads to conclusion that classical, ex cathedra approach is still prevailing.

The third group of statements was related to a degree of creativity in classroom. Results of respondents' agreement or disagreement with offered statements are presented in Table 3. 
Table 3. Results related to degree of creativity in classroom

\begin{tabular}{|c|c|c|c|}
\hline \multirow{2}{*}{ Statement } & \multicolumn{2}{|c|}{ M \pm SD } \\
\cline { 2 - 4 } & T (n=58) & S (n=387) & P* \\
\hline Students should be encouraged to be creative. & $4,793 \pm 0,487$ & $4,558 \pm 0,768$ & 0,002 \\
\hline Lessons need to be oriented towards new methods of learning. & $4,397 \pm 0,724$ & $4,289 \pm 0,918$ & 0,396 \\
\hline Teachers are the main instigators of students' creativity. & $3,707 \pm 0,973$ & $3,762 \pm 1,089$ & 0,715 \\
\hline Creativity of students depends on the characteristics of teachers. & $3,828 \pm 0,958$ & $4,041 \pm 0,959$ & 0,114 \\
\hline All student perceptions/experiences of a problem should be considered. & $3,690 \pm 0,863$ & $4,026 \pm 0,952$ & 0,012 \\
\hline It is more important to communicate with students than to lecture planned material. & $3,086 \pm 1,204$ & $3,858 \pm 1,069$ & 0,000 \\
\hline Students can guide running of lectures. & $3,293 \pm 0,955$ & $3,628 \pm 0,980$ & 0,015 \\
\hline Each problem has unique solution. & $1,655 \pm 0,965$ & $2,530 \pm 1,420$ & $<0,001$ \\
\hline so successfully pass the exam the student needs to answer the question exactly as it is & $1,879 \pm 1,027$ & $2,129 \pm 1,309$ & 0,100 \\
\hline Students can have their opinion about a problem that is completely different from \\
teachers' opinion. & $4,172 \pm 0,881$ & $3,912 \pm 1,137$ & 0,047 \\
\hline
\end{tabular}

T - Teacher; S - Student; M-mean; SD - standard deviation;

*t-test for independent samples

Opinions of respondents about statements related to creativity in teaching process are variegated. The results of research show that there are statistically significant differences for some of the statements, while differences in average grades are obvious for all statements. Both teachers and students think that students should be encouraged on creativity. It means that during lectures teachers should use new methods of learning and accept that it could be significant difference between their and students' opinions about the same thing. It is interesting to notice that both, teachers and students, think that teachers have main role in encouraging students to creativity and that efficiency of encouragement is dependent on personal characteristics of teachers. Also, it is necessary to point out differences in grades for statements "Each problem has unique solution" and "To successfully pass the exam the student needs to answer the question exactly as it is stated in literature". Since the classical - ex-cathedra approach in teaching process is still prevailing; one could expect higher agreement of teachers. Strange, but students agreed more with that statements. It is necessary to stress that the level of agreement is relatively low for both of them (average grades are about 2).

In the Chapter 2 different definitions of creativity were stated. So, the fourth group of statements offered respondents possibility to choose one or more of definition of term creativity (multiple choices were allowed). Results are presented in Table 4.

In the Chapter 2 different definitions of creativity were stated. So, the fourth group of statements offered respondents possibility to choose one or more of definition of term creativity (multiple choices were allowed). Results are presented in Table 4.

Results presented in Table 4 show that both, teachers and students, often connect creativity with "generating new ideas" $(65.5 \%$ of teachers and $68.2 \%$ of students). It is also the most often answer for students, after that follow "be nimble", "experimenting", "seeing the world in different ways" and "search for novelty". The most often answer for teachers is "thinking outside the box", after that follow "generate new ideas", "combining different ideas", "seeing the world in different ways" and "inventing, innovating and producing new things". The rarest answer in both groups of respondents was "adapt to the existing frameworks". It is expected because obedient adaptation to existing framework has nothing to do with creativity, unless if it is a new way of adaptation. 
Table 4. Results of respondents understanding of creativity

\begin{tabular}{|c|c|c|c|c|}
\hline \multirow{2}{*}{ Creativity means ... } & \multicolumn{2}{|c|}{$T(n=58)$} & \multicolumn{2}{|c|}{$S(n=387)$} \\
\hline & $f^{*}$ & $\%$ & $f^{*}$ & $\%$ \\
\hline generate new ideas & 38 & $65,5 \%$ & 264 & $68,2 \%$ \\
\hline thinking outside the box & 39 & $67,2 \%$ & 207 & $53,5 \%$ \\
\hline search beyond the obvious & 19 & $32,8 \%$ & 89 & $23,0 \%$ \\
\hline seeing the world in different ways & 34 & $58,6 \%$ & 209 & $54,0 \%$ \\
\hline inventing, innovating and producing new things & 31 & $53,4 \%$ & 201 & $51,9 \%$ \\
\hline adaptation of the things that someone else invented & 21 & $36,2 \%$ & 67 & $17,3 \%$ \\
\hline do things that nobody has done before & 19 & $32,8 \%$ & 142 & $36,7 \%$ \\
\hline do things that others have done before, but in a different way & 25 & $43,1 \%$ & 128 & $33,1 \%$ \\
\hline combining different ideas & 37 & $63,8 \%$ & 190 & $49,1 \%$ \\
\hline see unusual connections between existing things/concepts & 22 & $37,9 \%$ & 89 & $23,0 \%$ \\
\hline be nimble & 22 & $37,9 \%$ & 238 & $61,5 \%$ \\
\hline be curious & 25 & $43,1 \%$ & 202 & $52,2 \%$ \\
\hline search for novelty & 26 & $44,8 \%$ & 210 & $54,3 \%$ \\
\hline explore and discover new and unknown & 23 & $39,7 \%$ & 150 & $38,8 \%$ \\
\hline critically reflect on the current world & 20 & $34,5 \%$ & 71 & $18,3 \%$ \\
\hline adapt to the existing frameworks & 1 & $1,7 \%$ & 36 & $9,3 \%$ \\
\hline experiment & 28 & $48,3 \%$ & 230 & $59,4 \%$ \\
\hline take the risk & 19 & $32,8 \%$ & 198 & $51,2 \%$ \\
\hline analyze & 16 & $27,6 \%$ & 137 & $35,4 \%$ \\
\hline synthesize & 16 & $27,6 \%$ & 65 & $16,8 \%$ \\
\hline
\end{tabular}

T - Teacher; S - Student;

*- multiple choice

\section{Conclusions}

Since the main aim of this preliminary research was to investigate the awareness of teachers and students of the University of Mostar related to the necessity to enhance creativity within and by academic community, the authors could conclude that results of research completely fulfill that aim. Namely, the results of research presented in this paper show that teachers and students of University of Mostar are aware of necessity of creativity in teaching process. As it is expected, there are differences in opinions between respondents because creativity during lectures is differently experienced and vary from field to field and theme to theme. Although equally participation of both, teachers and students, in educational process is constantly pointed out, their roles, rights and obligations are different, so it is logical that their opinions are also different.

Evaluation of teachers' behavior related to creativity during the teaching process shows that there is statistically significant difference in opinions between teachers and students. It is obvious that teachers evaluated themselves better than students evaluated them. Generally, students think that teachers do not encourage them enough to be active participants of teaching process. Although teachers did not get high grades for some of specified activities, one could not say that they are not creative. But, according to students' opinions expressed in this research, prevailing model of teaching at University of Mostar is still ex cathedra, so it is necessary that all stakeholders make an additional effort to enhance creativity, not just in teaching process, but in research, management and other activities of University. Some preconditions for enhancing creativity were already done - the last Strategy of development of the University of Mostar 2012-2016 highlights the necessity of fostering creativity in all segments of University life.

The research presented in this paper is the first research related to creativity conducted at University of Mostar and it could be good base for further research in this field. It is important to stress that teachers had to evaluate themselves, so their results should be taken with caution. In order to get more relevant and objective data it is necessary to increase sample, validate the instrument of research and to include independent evaluators to get data relevant for successful decision making related to fostering creativity at University of Mostar.

\section{REFERENCES}

[1] Z. Fields, C.A. Bisschoff A Theoretical Model to Measure 
Creativity at a University, Journal of Social Sciences, No. 34, 47-59, 2013.

[2] P. Martin (ed.) Making space for creativity, Brighton: University of Brighton, Online available from https://www.brighton.ac.uk/creativity/Library/UofB_msfc-eb ook FINAL. pdf

[3] V. Majstorivić (ed.) Strategija Sveučilišta u Mostaru 2012-2016, Mostar, Sveučilište u Mostaru, 2012.

[4] D. Božanić O kreativnosti, Online available from http://www.psihologijaonline.com/psihologija-stvaralastva/8 4-o-kretivnosti

[5] M. Wynder Motivating creativity through appropriate assessment: lessons for management accounting educators, e-Journal of Business Education \& Scholarship of Teaching, 2008, Vol. 2, Iss. 2,12-27, Online available from http://www.ejbest.org

[6] S. Ozimec Odgoj kreativnosti: Kako prepoznati i poticati dječju kreativnost, Varaždin: Opći Savez društva "Naša djeca", 1987.

[7] I. Somolanji, L. Bognar Kreativnost u osnovnoškolskim uvjetima, Život i škola, 2007, No. 19, 87-94.

[8] P. Pylkkanen The Search for Meaning. The new spirit in science and philosophy, Wellingborough: Aquarian Press, 1989.
[9] L. Livingston Teaching creativity in higher education, Arts Education Policy Review, 2010, No. 111, 59-62.

[10] EUA Lisbon Declaration - Europe's Universities beyond 2010: Diversity with a Common Purpose, European University Association, online available from http://www.eua.be/ publications/eua-policy-positions.aspx

[11] EC Europe 2020 Flagship Initiative, European Commission, Online available from http://ec.europa.eu/europe2020/ documents/documents-and-reports/subject/strategic-docume nts/index_en.htm\#top

[12] EUA Smart People for Smart Growth: Statement by the European University Association on the EU Flagship Initiative "Innovation Union" of the Europe 2020 European Strategy for Smart, Sustainable and Inclusive Growth, European University Association, Online available from http://www.eua.be/publications/eua-reports-studies-and-occa sional-papers.aspx

[13] EUA Creativity in Higher Education: Report on the EUA Creativity Project 2006-2007, European University Association, Online available from http://www.eua.be /fileadmin/user upload/files/Publications/Creativity in high er_education.p $\overline{\mathrm{d} f}$

[14] Adobe How Educators are Handling the Creativity Challenge, Adobe, Online available http://www.adobe.com/sea/special/ creativity-report-sea/images/adobe_state_of_creativity_repor t_final.pdf 